\title{
Coronary artery bypass surgery in type 2 diabetic patients: predictors of mortality and morbidity
}

Younes Moutakiallah ${ }^{1,2^{*}}$ (D) Abdelatif Boulahya ${ }^{1,2}$, Aniss Seghrouchni ${ }^{1,2}$, Reda Mounir ${ }^{1,2}$, Noureddine Atmani ${ }^{1,2}$, Mohammed Drissi ${ }^{1,3}$, El Ghadbane Abdedaim Hatim ${ }^{1,3}$, Zouhair Lakhal ${ }^{1,4}$, lliyasse Asfalou ${ }^{1,4}$, Youssef El Bekkali ${ }^{1,2}$, Redouane Abouqal ${ }^{1,5}$ and Mahdi Aithoussa ${ }^{1,2}$

\begin{abstract}
Background: Coronary artery bypass grafting has been widely admitted in the therapeutic arsenal of coronary artery disease in diabetics with low morbi-mortality. However, it requires special management which may be challenging in low-volume centers especially in African countries. We aimed to analyze the outcome of coronary artery bypass graft in our diabetic population and define predictors of adverse events.
\end{abstract}

Patients and methods: We retrospectively enrolled 529 consecutive diabetic patients (type 2) who underwent onpump coronary artery bypass grafting at our institution between January 2000 and June 2018. The mean age was $61.1 \pm 8.3$ years with 4.04 as sex ratio (M/F) and 2.95 as mean EuroSCORE II. History of acute myocardial infarction, left main coronary artery stenosis, and three-vessel disease was present in respectively $58 \%, 26.1 \%$, and $72.2 \%$ of patients. The average number of bypass was $2.4 \pm 0.8$. Duration of cardiopulmonary bypass and aortic crossclamping were respectively $124.8 \pm 43.5$ and $79.7 \pm 32.9$ min.

Results: In-hospital mortality was $5.9 \%(n=31)$ and the late mortality was $6.9 \%(n=32)$. Duration of artificial ventilation, ICU stay, and postoperative stay were respectively $7 \mathrm{~h}, 44 \mathrm{~h}$, and 13 days. Postoperative complications were myocardial infarction, superficial wound infection, mediastinitis, and low cardiac output syndrome in respectively $9.1 \%, 25.5 \%, 3.8 \%$, and $12.7 \%$ of patients. Multivariable logistic regression analysis revealed that left ventricular ejection fraction $<40 \%(\mathrm{OR}=1.88 ; 95 \% \mathrm{Cl} 1.30-2.47 ; p=0.03)$, poor perioperative glycemic control (OR $=1.53 ; 95 \% \mathrm{Cl} 1.12-2.38 ; p=0.014)$, intra-aortic balloon pump insertion $(\mathrm{OR}=2.29 ; 95 \% \mathrm{Cl} 1.47-3.10 ; p<0.001)$, and postoperative cardiac complications $(\mathrm{OR}=2.01 ; 95 \% \mathrm{Cl} 1.23-2.78 ; p<0.001)$ were predictors of in-hospital mortality. Predictors of mediastinitis were obesity $(\mathrm{OR}=5.86 ; 95 \% \mathrm{Cl} 1.43-23.95 ; p=0.014)$, inotropic drugs use (OR $=8.14 ; 95 \% \mathrm{Cl} 1.57-42.34 ; p=0.013)$, chest reopening for bleeding (OR $=4.01 ; 95 \% \mathrm{Cl} 0.62-25.85 ; p=0.014)$, and blood transfusion ( $\mathrm{OR}=7.56 ; 95 \% \mathrm{Cl} 1.09-52.76 ; p=0.041$ ). Follow-up was $86.1 \%$ complete, with a mean follow-up of $63.5 \pm 48.3$ months (1-192 months), and cumulative survival at 5, 10, and 15 years was respectively $95.5 \pm 1.1 \%$, $86.3 \pm 2.9 \%$, and $76.9 \pm 6.9 \%$.

Conclusion: Even in low-volume centers in developing areas, coronary artery bypass surgery is an effective therapy for coronary artery disease in diabetic patients despite a relative high morbidity and mortality.

Keywords: Diabetes mellitus, Coronary artery bypass grafting surgery, Low-volume center, Low-income countries, Africa

\footnotetext{
*Correspondence: dryouns@hotmail.com

${ }^{1}$ Faculty of Medicine and Pharmacy, Mohammed V University, Rabat,

Morocco

${ }^{2}$ Cardiac Surgery Department, Mohammed V Teaching Military Hospital, Hay

Riyad, PB 10100 Rabat, Morocco

Full list of author information is available at the end of the article
} 


\section{Background}

Diabetes mellitus (DM), an important risk factor of coronary artery disease (CAD) $[1,2]$, is a rapidly progressing public health problem in our country, with a prevalence in adult population varying from $6.6 \%$ in 2000 to $12.4 \%$ in 2016 [3-5]. This unrestrained evolution of DM and CAD among our population has drastically modified our surgical activity formerly dominated by rheumatic valve disease and now balanced by coronary artery bypass grafting (CABG) which has been largely described by the most internationally accepted studies as the standard of care for CAD [6-8].

DM is constantly increasing throughout the world [9, 10], especially in developing countries, because of rapid changes in lifestyles and dietary habits [11]. However, these radical changes have not been followed, as is the case in developed countries, with adequate care. Therefore, diabetics in developing countries had more complications because of delayed diagnosis and treatment which might have a negative impact on surgical results [11].

Traditionally, DM has been associated with poor results and adverse outcomes after CABG for both the short term and long term [12-14]. However, several recent series conducted mainly in developed countries have shown that DM is not in itself an additional risk in CABG with almost similar results in diabetic and nondiabetic patients [12, 15-17]. However, can these results obtained in high-volume and experienced centers in high socio-economic countries be replicated in low-volume centers in developing areas such as Africa? This concern is largely justified by the frequency of co-morbidities and degenerative disorders which require special management and may be challenging in low-income African countries. The aim of the current study was to analyze the outcome of CABG in diabetic population and to define predictors of adverse events.

\section{Methods}

Study design

After approval of our institutional review board and registered in ISRCTN registry, we conducted an observational retrospective cohort study about outcomes of CABG in diabetic patients. We collected and analyzed the data of 529 consecutive type 2 diabetic patients who underwent on-pump CABG at our institution between January 2000 and June 2018. Data were extracted from preoperative and postoperative clinical notes, anesthesia and operating data records, intensive care unit (ICU) progress notes, and laboratory data. Patients were divided into two groups: insulin-treated group (IT group) $(n=322)$ and noninsulin-treated group (NIT group) $(n=207)$.

\section{Inclusion and exclusion criteria}

The inclusion criteria were all type 2 diabetic patients with diagnostic coronary artery disease and who underwent on-pump CABG. The exclusion criteria were type 1 diabetes and off-pump CABG.

\section{Definitions}

DM type 2 is defined according to the American Diabetes Association as fasting plasma glucose (FPG) $\geq 126$ $\mathrm{mg} / \mathrm{dl}$ or 2 -h plasma glucose $\geq 200 \mathrm{mg} / \mathrm{dl}$ during oral glucose tolerance test and A1c hemoglobin (HbA1c) $\geq$ $6.5 \%$ [2]. All patients underwent a systematic arterial ultrasound examination of the abdominal aorta, the supra-aortic trunks, and the lower extremity arteries for peripheral atherosclerosis. In case of significant stenosis, a CT scan was performed. Polyvascular atherosclerotic disease (PVAD) was defined as follows a history of vascular reconstruction; bypass surgery or percutaneous intervention on carotid, abdominal aorta, or any peripheral artery for atherosclerotic lesion; documented aortic aneurysm; or significant atherosclerotic arterial stenosis. Anemia was defined as hemoglobin level below $11 \mathrm{~g} / \mathrm{dl}$ for women and $13 \mathrm{~g} / \mathrm{dl}$ for men.

\section{Diabetes management}

Anti-diabetic treatment was substituted 2 days before surgery by a standard sliding scale subcutaneous insulin injection. In the operating room and ICU, blood glucose level (BGL) was routinely measured and controlled by intermittent intravenous injection of insulin or by continuous intravenous insulin (50 IU of insulin in $50 \mathrm{ml}$ $0.9 \%$ normal saline) adjusted to target intraoperative BGL between 120 and $180 \mathrm{mg} / \mathrm{dl}$. In the ward, patients were switched back to subcutaneous insulin injection and then resumption of the preoperative anti-diabetic regimen usually on the fifth postoperative day.

\section{Operative protocol}

All patients were operated according to the same protocol by the same team. General anesthesia was made by cisatracurium besylate, midazolam, thiopental, and propofol. After sternotomy, the pericardium space was opened and the internal thoracic arteries (ITA) and the saphenous vein graft (SVG) were harvested. Initially, for almost all diabetic patients, only the left internal thoracic artery (LITA) was harvested in addition to the SVG until 2010, when we started to harvest both skeletonized ITA. Bilateral internal thoracic artery (BITA) was avoided in patients with one of the following criteria: age $>70$ years, obesity, and chronic obstructive pulmonary disease.

Cardiopulmonary bypass ( $\mathrm{CPB}$ ) conventionally performed by standard aortic and venous cannulation was conducted under moderate systemic hypothermia $\left(32{ }^{\circ} \mathrm{C}\right)$. Myocardial protection was achieved with antegrade cold $\left(4^{\circ} \mathrm{C}\right)$ crystalloid St. Thomas cardioplegia and/or antegrade cold blood cardioplegia. We carried on by the right coronary artery anastomosis, then the left 
marginal arteries, and finally the left anterior descending artery. After aortic clamp release and heart defibrillation, proximal anastomoses to the ascending aorta were performed by partial aortic clamping.

\section{Postoperative management and follow-up}

Postoperative events and results are described as follows: in-hospital mortality indicates death occurring during the hospitalization in which CABG was performed, an early complication was defined as an event occurring during hospitalization, and a late complication was defined as an event occurring after discharge. A bleeding event is any episode of major internal or external bleeding that causes death, hospitalization, or permanent injury or required blood transfusion. A neurologic event includes any new, temporary, or permanent focal or global neurologic deficit. Cardiac complication was defined by one of the following: inotropic drug $\geq 72 \mathrm{~h}$, acute myocardial infarction (AMI), low cardiac output syndrome (LCOS), insertion of intra-aortic pump balloon (IABP), return to operating room for bleeding or tamponade, new onset of atrial fibrillation (A. Fib), permanent pacemaker placement, or in-hospital cardiac arrest. Respiratory complication was defined by one of the following: lung collapse, atelectasis, acute respiratory distress syndrome, respiratory failure and pleural effusions, duration of mechanical ventilation $\geq 24 \mathrm{~h}$, re-intubation, or tracheostomy. Infective complication was defined by one of the following: pneumonia, sternum or leg wound infection, mediastinitis, or sepsis. Renal complication was defined by new-onset renal failure (serum creatinine elevation $>2$ times) or new-onset renal replacement therapy.

Follow-up data were obtained from our local database. After discharge, all patients were included in our scheduled follow-up protocol with routine clinical controls at $1,3,6$, and 12 months and annually afterwards. Followup data were provided either routinely by our outpatient clinic evaluation (medical visits of the systematic and programmed controls) or by telephone interviews with patients, relatives or referring physicians. The control was based on clinical examination, electrocardiogram, chest X-ray, and echocardiography. In case of residual angina, exertional dyspnea, and electrical or echocardiographic signs of myocardial ischemia, patients were explored by stress test and coronary angiogram.

\section{Statistical analysis}

The statistical analysis was performed by IBM statistical package software for social sciences 19.0 (SPSS, Chicago, IL, USA). Data were presented as mean \pm standard deviation (SD), median (range), and $n$ (\%). For comparisons, chi-square test or Fisher's test were used for categorical variables and Student's $t$ test or non-parametric Wilcoxon rank-sums test for continuous variables. Survival curves were made with Kaplan-Meier method with group comparisons by log-rank test. Independent predictors of inhospital mortality and adverse outcomes with a $p$ value of less than 0.2 on univariate analysis were considered in the multivariate analysis using stepwise selection. Results are expressed using odds ratio (OR). For all analyses, $p$ values $<0.05$ were considered statistically significant.

\section{Results}

Total population: See Table 1.

\section{Baseline characteristics}

The mean age of patients was $61.1 \pm 8.3$ years with 4.04 as sex ratio $(\mathrm{M} / \mathrm{F})$. More than three cardiovascular risk factors were found in $32.9 \%$ of patients, and mean body mass index was $26.5 \pm 3.4 \mathrm{~kg} / \mathrm{m}^{2}$. Previous percutaneous coronary intervention and vascular surgery were respectively noticed in $10 \%$ and $1.9 \%$ of patients. Angina was present in $93.8 \%$ of patients, and $42 \%$ had Canadian Cardiovascular Society class 3-4. New York Heart Association (NYHA) class 3-4 was found in $23.6 \%$ of patients. A. Fib and chest X-ray cardiomegaly were detected respectively in $1.7 \%$ and $34.6 \%$ of patients. Left ventricular (LV) ejection fraction and systolic pulmonary arterial pressure were respectively $55 \%$ (range $20-80 \%$ ) and $25 \mathrm{mmHg}$ (range $12-96 \mathrm{mmHg}$ ). More than mild mitral regurgitation was found in $12.7 \%$ of patients. EuroSCORE II and $\mathrm{HbA}_{1} \mathrm{c}$ were respectively 1.68 (range $0.7-47$ ) and $8 \%$ (range 5.3-14.9\%).

\section{Operative data}

$\mathrm{CPB}$ and aortic cross-clamping times were respectively $124.8 \pm 43.5 \mathrm{~min}$ and $79.7 \pm 32.9 \mathrm{~min}$. Cardioplegia protocol consisted of three categories: cold blood cardioplegia (45.7\%), cold crystalloid (39.5\%), and mixed cardioplegia (14.7\%), and $10 \%$ of patients had hot reperfusion just before aortic clamp release. The used grafts were LITA, SVG, and RITA in respectively $97.2 \%, 78.4 \%$, and $17.4 \%$ of patients with $20.6 \%$ as rate of all arterial revascularization. Complete revascularization was achieved in $50.5 \%$ of patients, and the main reason of the incomplete revascularization, as mentioned on individual surgical reports, was the complexity of lesions and the poor quality of coronary arteries which were of small caliber and unsuitable for bypass. CABG was associated to other procedures in 53 patients (10\%) and consisted of 24 aortic valve replacements (4.5\%), 10 carotid surgeries, 9 mitral valve replacements, 3 mitral and aortic valve replacements, 1 mitral valve replacement with tricuspid repair, $1 \mathrm{LV}$ aneurysm repair, 1 postinfarction ventricular septal defect (VSD) closure, $1 \mathrm{LV}$ aneurysm repair with VSD closure, 1 abdominal aortic aneurysm repair, and 1 peripheral vascular surgery. Those associated procedures were significantly associated with high rate of mortality 
Table 1 Baseline and operative characteristics and outcomes of all patients. Data are expressed as $n$ (\%) for categorical variables, mean \pm standard deviations, or median (range) for continuous variables

\begin{tabular}{|c|c|}
\hline Variable & \\
\hline Age $>70$ years & $86(16.3 \%)$ \\
\hline Female, $n(\%)$ & $105(19.9 \%)$ \\
\hline \multicolumn{2}{|l|}{ Cardiovascular risk factor } \\
\hline Hypertension, $n(\%)$ & $267(50.5 \%)$ \\
\hline Hyperlipidemia, $n(\%)$ & $206(38.9 \%)$ \\
\hline Smoking, $n(\%)$ & $288(54.4 \%)$ \\
\hline \multicolumn{2}{|l|}{ Comorbidities } \\
\hline Renal failure (severe or more), $n(\%)$ & $31(5.9 \%)$ \\
\hline Stroke, $n(\%)$ & $15(2.8 \%)$ \\
\hline Chronic obstructive pulmonary disease, $n(\%)$ & $94(17.8 \%)$ \\
\hline Anemia, $n(\%)$ & $117(22.1 \%)$ \\
\hline Polyvascular atherosclerotic disease, $n(\%)$ & $97(18.3 \%)$ \\
\hline Acute myocardial infarction $<3$ months, $n(\%)$ & $193(36.5 \%)$ \\
\hline \multicolumn{2}{|l|}{ Echocardiographical and coronary angiogram finding } \\
\hline Left ventricular ejection fraction < 40\%, $n(\%)$ & $66(12.5 \%)$ \\
\hline Pulmonary hypertension, $n(\%)$ & $183(34.6 \%)$ \\
\hline Tri-vessels disease, $n(\%)$ & $382(72.2 \%)$ \\
\hline Left main coronary artery stenosis, $n(\%)$ & $138(26.1 \%)$ \\
\hline \multicolumn{2}{|l|}{ Operative parameters } \\
\hline Urgency-emergency, $n$ (\%) & $66(12.5 \%)$ \\
\hline Distal anastomosis per patient & $2.3 \pm 0.8$ \\
\hline Bilateral internal thoracic artery use, $n(\%)$ & $88(16.6 \%)$ \\
\hline "Y" anastomosis, $n(\%)$ & $43(8.1 \%)$ \\
\hline Associated procedures, $n(\%)$ & $53(10 \%)$ \\
\hline \multicolumn{2}{|l|}{ Postoperative course } \\
\hline In-hospital deaths, n (\%) & $31(5.9 \%)$ \\
\hline Ventilator support, (hours) & $7(2-1560)$ \\
\hline Intensive care unit stay, (hours) & $44(18-1560)$ \\
\hline Hospital stay (days) & $13(2-106)$ \\
\hline Cardiac complications, n (\%) & $117(22.1 \%)$ \\
\hline Infective complications, n (\%) & $142(26.8 \%)$ \\
\hline Respiratory complications, $n$ (\%) & $92(17.4 \%)$ \\
\hline Renal failure, $n(\%)$ & $68(12.9 \%)$ \\
\hline Cerebro-vascular accident, $n$ (\%) & $11(2.1 \%)$ \\
\hline
\end{tabular}

$(p<0.001)$ and all cardiac complications $(p<0.001)$. The weaning of CPB was difficult in 48 patients (9.1\%) and needed inotropic drug use and intra-aortic balloon pump insertion in 40 patients (7.6\%).

\section{Postoperative course}

The postoperative course was marked by complications in $44 \%$ of patients; half was benign in nature (paroxystic A.
Fib, transient hypoxemia, and poor glycemic control). Cardiac complications were present in $22.1 \%$ of patients and were as follows: inotropic drugs use $\geq 72 \mathrm{~h}(19.5 \%)$, LCOS (12.7\%), IABP insertion (9.3\%), and AMI (9.1\%). However, infections were the most frequent complications (26.8\%); the rate of mediastinitis was $3.8 \%$ while wound infection and pneumonia rates were respectively $25.5 \%$ and $8.7 \%$. Glucose level was poorly controlled in $34.6 \%$ of patients. Univariate and multivariate binary logistic regression analysis identified several independent predictors of inhospital and late mortality and major adverse cardiac and cerebral event (MACCE) (Tables 2 and 3).

\section{Intergroup comparison}

We compared IT and NIT group data and found that preoperative parameters were quite similar except for some variables such as diabetes duration, anemia, PVAD, degenerative retinopathy and nephropathy, EuroSCORE II, fasting plasma glucose, $\mathrm{HbA}_{1} \mathrm{c}$, and $\mathrm{C}$ reactive protein which were worse in the IT group. However, gastro-duodenal ulcer was more frequent in the NIT group $(6.3 \%$ vs. $1.9 \%$, $p=0.01)$. There were no significant differences in echocardiography and coronary angiogram findings.

Operative data showed an almost complete similarity between the two groups with no significant difference in surgical techniques, number of distal anastomoses, and grafts used except for complete revascularization which was significantly more reached in the NIT group.

In contrast, outcomes were clearly different, since the IT group showed significantly higher morbidity and mortality. All cardiac complications were significantly more frequent in the IT group except for the rate of AMI which was higher in the IT group without crossing the threshold of significance (10.6\% vs. $6.8 \%, p=0.163)$. Pneumonia and superficial wound infection rates were also significantly higher in the IT group $(29.5 \%$ vs. $19.3 \%, p=0.01$; and $11.2 \%$ vs. $4.9 \%, p=0.011$ respectively), but the difference was not significant for mediastinitis $(4.3 \%$ vs. $2.9 \%, p=0.49)$ (Table 4$)$.

\section{Follow-up and long-term outcomes}

Follow-up was closed on June 1, 2019, and was 86.1\% complete, with a cumulative duration of follow-up of 30 , 692 patient-years and a mean follow-up period of $63.5 \pm$ 48.3 months (1-192 months). Mortality rate was 6.9\% ( $n=$ 32 ), and cumulative survival calculated by Kaplan-Meier method at 5,10 , and 15 years was respectively $95.5 \pm 1.1 \%$, $86.3 \pm 2.9 \%$, and $76.9 \pm 6.9 \%$ (Fig. 1), with no significant difference at 15 years between the IT and NIT groups (respectively $72.2 \pm 13.5 \%$ vs. $79.5 \pm 7.8 \%$; $p=0.311$ ) (Fig. 2 ). Similarly, there was no significant difference between complete and incomplete revascularization (respectively $74.9 \pm 9.8 \%$ vs. $80.1 \pm 8.2 \% ; p=0.69$ ) (Figs. 3 and 4 ). 
Table 2 Independent predictors of in-hospital mortality on binary logistic regression analysis (all patients)

\begin{tabular}{|c|c|c|c|c|c|c|}
\hline \multirow[t]{2}{*}{ Characteristics } & \multicolumn{3}{|c|}{ Univariate analysis } & \multicolumn{3}{|c|}{ Multivariate analysis } \\
\hline & $\mathrm{OR}$ & $95 \% \mathrm{Cl}$ & $p$ value & $\mathrm{OR}$ & $95 \% \mathrm{Cl}$ & $p$ value \\
\hline Left ventricular ejection fraction $<40 \%$ & 1.06 & $0.46-1.66$ & $<0.001$ & 1.88 & $1.30-2.47$ & 0.003 \\
\hline Left ventricular diastolic dysfunction & 1.17 & $0.68-1.66$ & $<0.001$ & 1.28 & $0.14-9.20$ & 0.008 \\
\hline Right ventricular dysfunction & 2.83 & $1.64-4.01$ & $<0.001$ & 1.28 & $0.34-2.23$ & 0.008 \\
\hline Poor glycemic control & 3.27 & $2.95-4.63$ & 0.001 & 1.53 & $1.12-2.38$ & 0.014 \\
\hline Low cardiac output syndrome & 4.29 & $3.80-4.77$ & $<0.001$ & 1.58 & $0.87-2.29$ & $<0.001$ \\
\hline Intra-aortic balloon pump insertion & 4.53 & $3.95-5.10$ & $<0.001$ & 2.29 & $1.47-3.10$ & $<0.001$ \\
\hline Cardiac complications & 5.76 & $5.15-6.38$ & $<0.001$ & 2.01 & $1.23-2.78$ & $<0.001$ \\
\hline Postoperative renal failure & 3.88 & $3.38-4.38$ & $<0.001$ & 1.47 & $0.93-2.02$ & $<0.001$ \\
\hline Postoperative stroke & 3.12 & $1.73-4.50$ & $<0.001$ & 1.96 & $1.05-2.88$ & $<0.001$ \\
\hline Tracheal re-intubation & 5.20 & $4.11-6.28$ & $<0.001$ & 2.46 & $1.44-3.49$ & $<0.001$ \\
\hline Respiratory complications & 2.58 & $2.10-3.06$ & $<0.001$ & 1.04 & $0.98-1.75$ & 0.035 \\
\hline
\end{tabular}

$O R$ odds ratio, $\mathrm{Cl}$ confidence interval

Exertional angina and NYHA class 3-4 were respectively observed in $6.1 \%$ and $5.6 \%$ of patients. Rehospitalization for MACCE was observed in $26.8 \%$ of patients (27.2\% of cardiac events and $1.8 \%$ of stroke). Myocardial revascularization was needed in $6.9 \%$ of patients (1 redo CABG because of graft failure and 30 percutaneous coronary interventions). There was no significant difference between IT and NIT groups except for hospitalizations for heart failure $(8.6 \%$ vs. $1.7 \% ; p=0.002)$.

In contrast, some variables were identified in univariate analysis as having a protector effect on late outcome such as BITA use (OR 1.53, 95\% CI 1.01-2.5; $p<0.001$ ), complete revascularization (OR 1.31, 95\% CI 0.48-1.71; $p=0.03$ ), all-arterial revascularization (OR 1.62, 95\% CI $0.87-1.93 ; p=0.008$ ), and hot blood reperfusion (OR 1.42 , 95\% CI $1.10-1.83 ; p=0.08$ ), but on multivariate analysis, only complete revascularization (OR 1.70, 95\%
CI 1.12-2.31; $p=0.04$ ) and hot blood reperfusion (OR 1.22 , 95\% CI $1.06-1.80 ; p=0.02$ ) were statistically significant predictors of better outcome.

\section{Discussion}

As the main finding of our study, CABG can provide relatively good results in diabetic patients with acceptable morbidity and mortality even in low-volume centers in low-middle-income countries. In addition, we have identified several parameters as independent predictors of in-hospital mortality (Table 3). Indeed, our in-hospital mortality rate was relatively high in comparison with large series in developed countries [13, 16, 18, 19], with also a high incidence of postoperative complications.

Surely, the literature had widely debated and treated the outcome and results of CABG in DM in all its aspects, but unfortunately, it is largely dominated by

Table 3 Independent predictors of late mortality and major adverse cardiovascular and cerebral events on binary logistic regression analysis (all patients)

\begin{tabular}{|c|c|c|c|c|c|c|}
\hline \multirow[t]{2}{*}{ Characteristics } & \multicolumn{3}{|c|}{ Univariate analysis } & \multicolumn{3}{|c|}{ Multivariate analysis } \\
\hline & $\overline{\mathrm{OR}}$ & $95 \% \mathrm{Cl}$ & $p$ value & $\mathrm{OR}$ & $95 \% \mathrm{Cl}$ & $p$ value \\
\hline Age $>70$ years & 2.01 & $1.18-3.41$ & 0.010 & 2.93 & $1.47-5.83$ & 0.002 \\
\hline Female sex & 1.21 & $0.37-1.40$ & 0.048 & 1.40 & $1.20-1.80$ & 0.009 \\
\hline Chronic obstructive pulmonary disease & 1.97 & $1.19-3.28$ & 0.009 & 2.07 & $1.01-4.23$ & 0.047 \\
\hline Anemia & 2.40 & $1.48-3.91$ & $<0.001$ & 1.97 & $1.03-3.80$ & 0.042 \\
\hline Left atrium dilation & 1.94 & $1.27-2.95$ & 0.002 & 2.16 & $1.01-4.61$ & 0.046 \\
\hline Lower extremity arterial disease & 1.80 & $1.41-2.32$ & $<0.001$ & 1.68 & $1.09-2.59$ & 0.018 \\
\hline Electrical heart defibrillation & 1.92 & $1.27-2.92$ & 0.002 & 2.25 & $1.23-3.89$ & 0.004 \\
\hline Postoperative acute myocardial infarction & 5.07 & $2.32-11.07$ & $<0.001$ & 5.72 & $1.87-17.46$ & 0.002 \\
\hline Chest reopening for bleeding & 4.61 & $1.48-14.36$ & 0.008 & 7.72 & $1.30-45.85$ & 0.025 \\
\hline Prolonged ventilator support & 1.02 & $1.01-1.04$ & 0.001 & 1.02 & $1.00-1.04$ & 0.046 \\
\hline Prolonged postoperative stay & 1.04 & $1.02-1.07$ & $<0.001$ & 1.04 & $1.00-1.08$ & 0.043 \\
\hline
\end{tabular}

$O R$ odds ratio, $\mathrm{Cl}$ confidence interval 
Table 4 Baseline characteristics, operative data, and outcome: comparison between insulin-treated and non-insulin-treated groups. Data are expressed as mean \pm SD, median (range), and $n(\%)$

\begin{tabular}{|c|c|c|c|}
\hline Variable & IT group, $n=322$ & NIT group, $n=207$ & $p$ value \\
\hline \multicolumn{4}{|l|}{ Baseline characteristics } \\
\hline Diabetes duration (months) & $120(1-648)$ & $84(0-468)$ & $<0.001$ \\
\hline Peripheral vascular surgery, $n$ (\%) & $9(1.7)$ & $1(0.2)$ & 0.009 \\
\hline Renal failure (severe or more), $n(\%)$ & $22(6.8)$ & $9(4.3)$ & 0.27 \\
\hline Chronic obstructive pulmonary disease, $n(\%)$ & $62(19.3)$ & $32(15.5)$ & 0.29 \\
\hline Anemia, $n(\%)$ & $81(25.2)$ & $36(17.4)$ & 0.04 \\
\hline Polyvascular atherosclerotic disease, $n(\%)$ & $70(21.7)$ & $27(13)$ & 0.01 \\
\hline Retinopathy and/or nephropathy, $n$ (\%) & $36(11.6)$ & $8(3.9)$ & 0.015 \\
\hline EuroSCORE II & $1.9(0.7-47)$ & $1.4(0.7-32.8)$ & 0.001 \\
\hline A1c hemoglobin (\%) & $8.5(5.8-14.9)$ & $7.3(5.3-13.8)$ & $<0.001$ \\
\hline \multicolumn{4}{|l|}{ Operative data } \\
\hline Urgency-emergency, $n$ (\%) & $43(13.4)$ & $23(11.1)$ & 0.58 \\
\hline Distal anastomosis per patient & $2.3 \pm 0.8$ & $2.4 \pm 0.8$ & 0.1 \\
\hline Complete revascularization, $n$ (\%) & $151(46.9)$ & $116(56)$ & 0.04 \\
\hline All arterial revascularization, $n(\%)$ & $65(20.2)$ & $44(21.3)$ & 0.84 \\
\hline Difficult weaning of cardio-pulmonary bypass, $n(\%)$ & $36(11.2)$ & $12(5.8)$ & 0.04 \\
\hline Intra-aortic balloon pump insertion, $n(\%)$ & $31(9.6)$ & $9(4.3)$ & 0.03 \\
\hline \multicolumn{4}{|l|}{ Postoperative course } \\
\hline In-hospital deaths, $n$ (\%) & $24(7.5)$ & $7(3.4)$ & 0.036 \\
\hline Ventilator support (hours) & $8(3-1560)$ & $6(2-524)$ & $<0.001$ \\
\hline Intensive care unit stay (hours) & $44(18-1560)$ & $44(18-528)$ & 0.001 \\
\hline Postoperative stay (days) & $13(2-106)$ & $13(2-53)$ & 0.09 \\
\hline Cardiac complications, n (\%) & $82(25.5)$ & $35(16.9)$ & 0.024 \\
\hline Infective complications, n (\%) & $102(31.7)$ & $40(19.3)$ & 0.002 \\
\hline Respiratory complications, $n(\%)$ & $68(21.1)$ & $24(11.6)$ & 0.005 \\
\hline Renal failure, $n(\%)$ & $50(15.5)$ & $18(8.7)$ & 0.024 \\
\hline Cerebro-vascular accident, $n(\%)$ & $8(2.5)$ & $3(1.5)$ & 0.541 \\
\hline Poor glycemic control, $n$ (\%) & $134(41.6)$ & $49(23.7)$ & $<0.001$ \\
\hline
\end{tabular}

series of high-volume centers in developed countries endowed with important logistics, modern hospitals with sophisticated medical equipment, good organization of the health care systems, and a high expertise of the practitioners. However, what about the situation in small centers in developing countries? In our daily practice, we are always extrapolating data from experiences of centers which share few things with our realities. Our study has the advantage to reflect as closely as possible the real-life situation in centers like ours and put the spotlight on the difficulties faced daily to perform CABG in "our" diabetic patients who present a high prevalence of chronic diabetic complications with microvascular lesions which were mainly due to non-compliance with diet, medications, lack of therapeutic education, and delay between the onset of diabetes and diagnosis time. Chadli et al. found in an epidemiologic study that the majority of diabetic patients in our country had at least one diabetes-associated complication and did not achieve the recommended triple target of glycemic, blood pressure and lipid control, suggesting that there is a huge gap between evidence-based diabetes management and real-life practice [20]. Bos et al. stipulated that most diabetic patients in northern Africa were unaware of their complications, and a high percentage of patients with severe complications had never been consulted by a specialist before [11]. Similarly, our patients referred for CABG often had severe diabetic complications and comorbidities such as micro- and macroangiopathy, renal failure, PVAD, and anemia, and frequently, they have never had an 


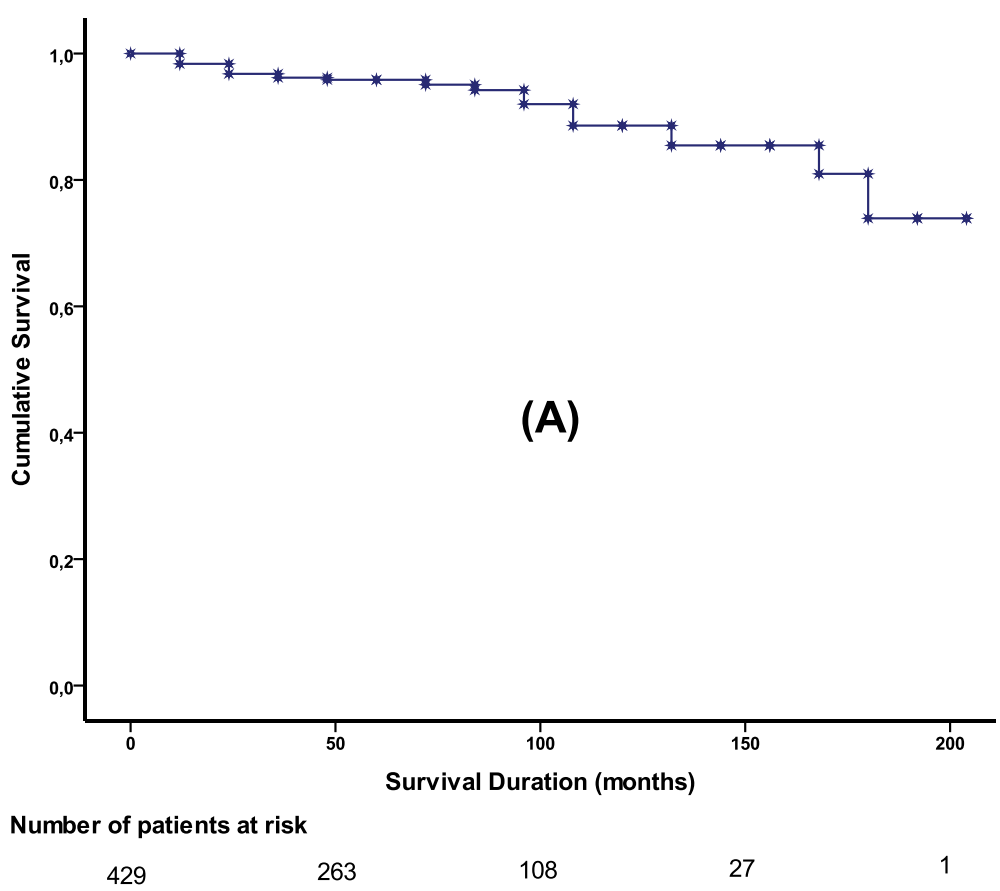

Fig. 1 Kaplan-Meier survival curve (A) for the whole cohort with all patients enrolled in the study

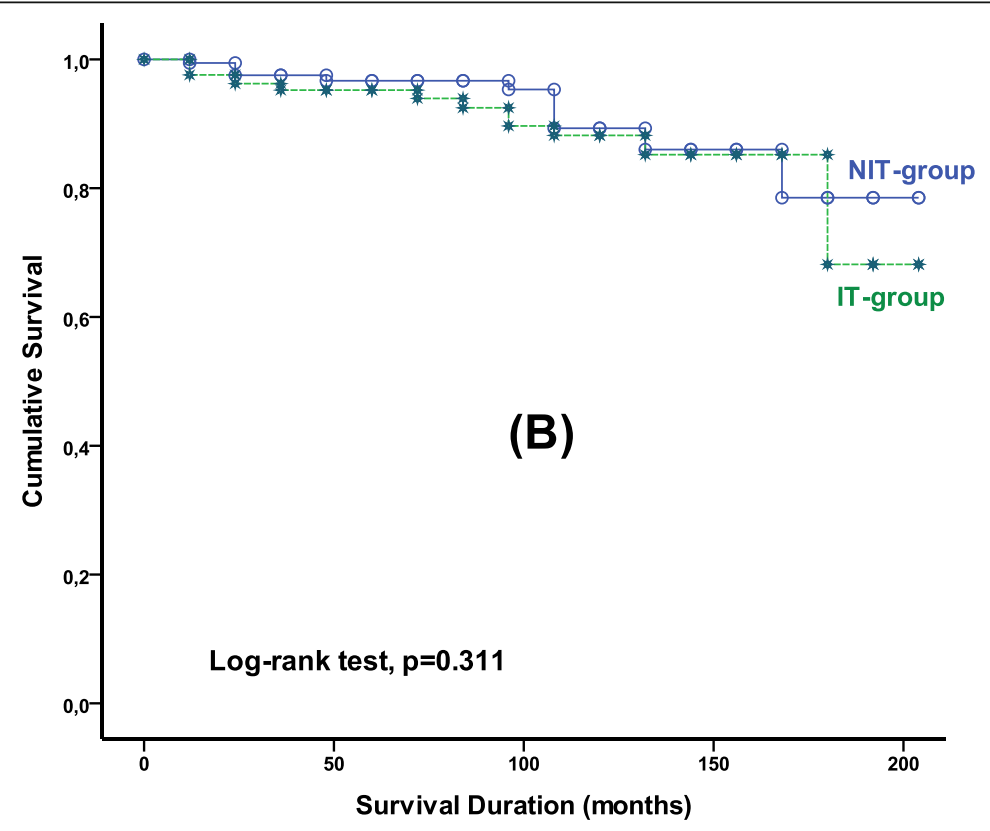

Number of patients at risk

$\begin{array}{lllll}\text { IT-group } 180 & 105 & 47 & 14 & 1 \\ \text { NIT-group } 249 & 158 & 61 & 12 & 1 \\ & & & & \\ \text { IT: Insulin-treated } & & & & \\ \text { NIT: Non-insulin-treated } & & \end{array}$

Fig. 2 Kaplan-Meier survival curve (B) for the whole cohort with all patients enrolled in the study with comparison between insulin-treated $(n=$ 322) and non-insulin-treated $(n=207)$ patients. IT: insulin-treated, NIT: non-insulin-treated 


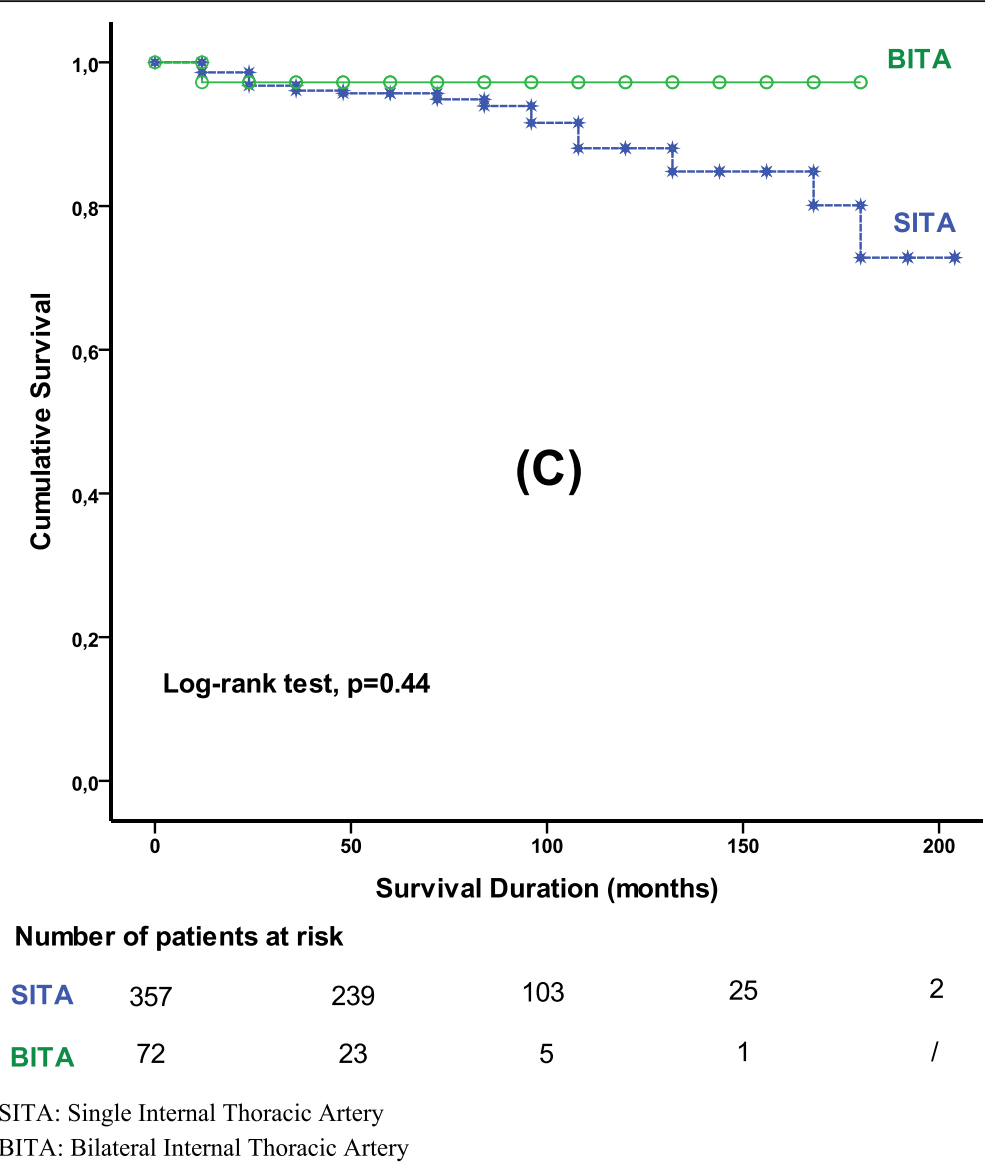

Fig. 3 Kaplan-Meier survival curve (C) for the whole cohort with comparison between patients who received bilateral internal thoracic artery use $(n=88,16.6 \%)$ and single internal thoracic artery $(n=441,83.4 \%)$. SITA: single internal thoracic artery. BITA: bilateral internal thoracic artery

evaluation of their cardiovascular system until after the declaration of complications such as inaugural AMI whose rate in our series remains very high.

We experienced that perioperative management of diabetes is one of the key of safe, secure, and efficient CABG. Poor perioperative glycemic control was clearly identified in our study as an independent predictor of in-hospital mortality, MACCE, and mediastinitis. That has been shared by most investigators who have focused on the association between perioperative hyperglycemia and mortality after CABG [21-23]. Ujueta et al. mentioned that peri-procedural BGL is associated with adverse clinical outcomes, by the bias of mechanisms of harm including increased inflammation, platelet reactivity, and endothelial dysfunction [24]. Magaji et al. showed the clear benefit of maintaining BGL between 110 and $140 \mathrm{mg} / \mathrm{dl}$ in immediate postoperative cardiac surgery by adopting a continuous insulin injection protocol for both glycemic control and hypoglycemia prevention [25].

Several studies had shown that insulin therapy was associated with higher mortality and morbidity $[12-14,18,26$,
27]. In our study, it has been associated in univariate analysis to higher in-hospital mortality and all adverse postoperative events, but it has not been identified in multivariate analysis as an independent predictor. That association might be explained by the fact that insulin therapy in our practice was usually indicated to more severe patients or after failure of conventional diet-oral hypoglycemic drugs; IT group had significantly older diabetes and more diabetes-related comorbidities (PVAD, anemia, higher EuroSCORE II, micro-angiopathy, and poor glycemic control). However, this needs more investigations to be proven.

Certainly, infection of incision sites is one of the most common complications after CABG in diabetic patients. Slightly more than a quarter of our patients presented infection which dominated by superficial and deep wound infection while mediastinitis rate was lesser. The incidence of infective complications was strongly associated with perioperative poor glycemic control. Several independent predictors of mediastinitis were identified in multivariate analysis: age, diabetes duration, obesity, poor perioperative glycemic control, prolonged ICU stay, inotropic support, chest reopening for bleeding, and 


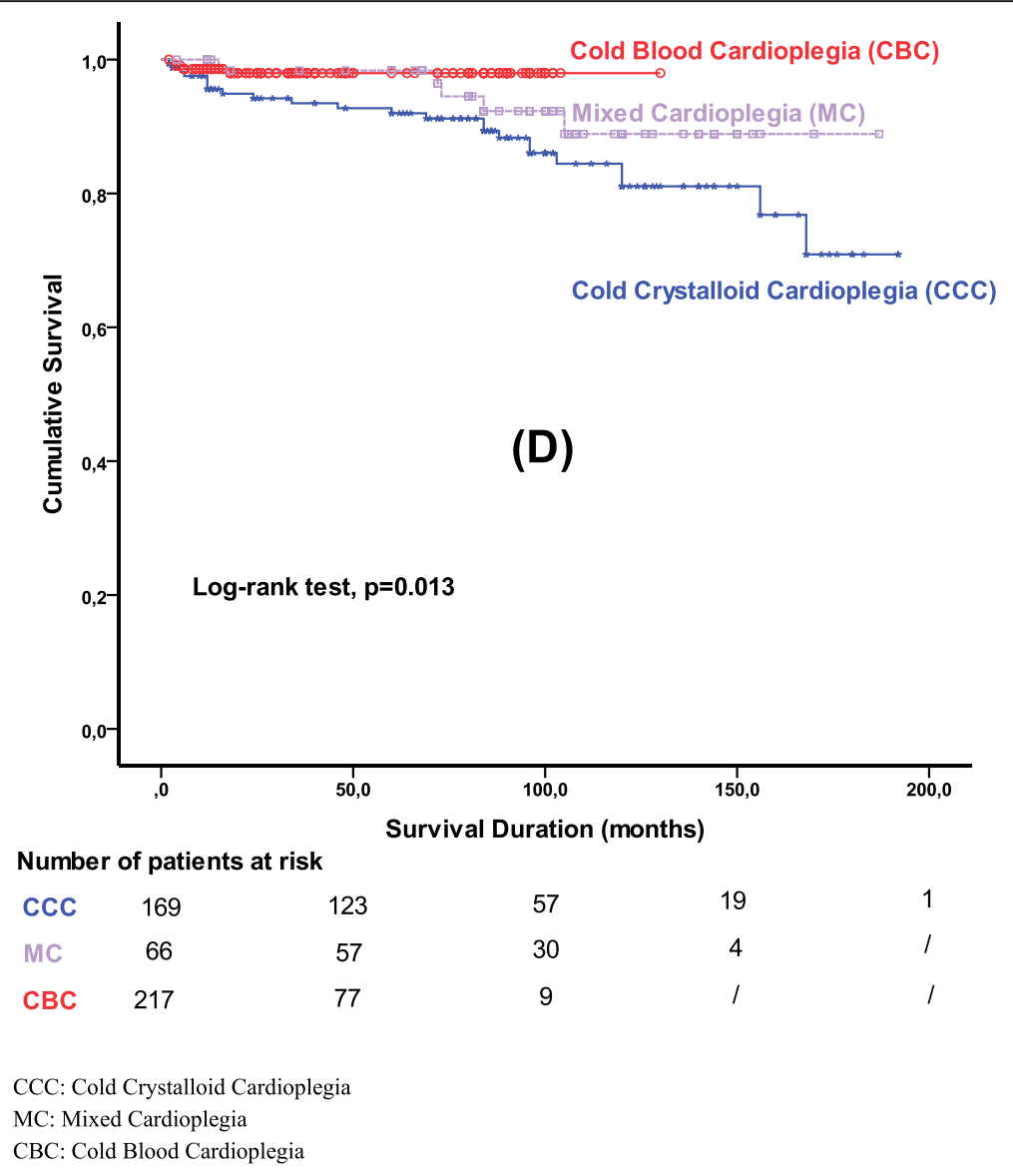

Fig. 4 Kaplan-Meier survival curve (D) for the whole cohort with comparison between cardioplegia protocols: cold blood cardioplegia ( $n=242$, 45.7\%), mixed cardioplegia ( $n=78,14.7 \%)$, and cold crystalloid cardioplegia $(n=209,39.5 \%)$. CCC: cold crystalloid cardioplegia, MC: mixed cardioplegia, CBC: cold blood cardioplegia

blood transfusion. However, BITA was indicated in the univariate analysis but was not significant in multivariate analysis as an independent predictor of mediastinitis. Even if several recent publications [28, 29] claimed that BITA use has not been associated with an increased risk of mediastinitis compared to SITA, the debate remains; Taggart et al. [30] had published the 5-year results of ART investigation and found that BITA was significantly associated with higher rate of both sternal wound complications and sternal reconstructions without benefit of survival or freedom from adverse events at 5 years. However, it seems that the risk can be lowered if graft harvesting was made by skeletonized fashion with meticulous attention to preserve sternal blood flow [31, 32].

Several studies have shown the superiority of arterial grafts over venous grafts in terms of long-term survival, need of repeated revascularization, and graft failure [28, $29,31,32$ ] without impact on in-hospital mortality [33]. But in our practice, and for a long time, we considered diabetes as an absolute contraindication to BITA harvesting because of the "inevitable and frightening" mediastinitis. This situation has been a real obstacle to the development of all arterial revascularization strategies even in case of young and low-risk patients. Lately, since 2010, we have changed this paradigm and adopted a cautious and progressive strategy towards using skeletonized BITA [5]. There was no significant difference of mediastinitis rate between BITA and SITA use $(6.8 \%$ vs. $3.2 \%, p=0.121$ ) (see Additional file 1: Table S1). Moreover, BITA was associated in univariate analysis with a protective effect on survival as well as complete revascularization. That concept was confirmed by many studies which have suggested a survival benefit for CABG versus percutaneous coronary intervention in DM, which can be due to the completeness of revascularization and to the good long-term patency of ITA over SVG [33-35].

\section{Limitations of the study}

Several important limitations exist in the current study. Mainly, it is limited by its mono-centric observational retrospective nature. The period of recruitment is too 
long, and the population is too small, which is an obstacle to draw strong conclusions. Some detailed data was not always available in our registry such as SYNTAX score and HbA1c measurement which was not a routine practice before 2015. The follow-up was only $86.1 \%$ completed and does not include a systematic angiographic control of the patency of grafts and anastomoses. Information about the main cause of death was not always available. The multivariable analysis of inhospital mortality may be underpowered because of the relatively small number of deaths.

\section{Conclusion}

Even in low-volume centers in developing areas, CABG is an effective therapy for CAD in diabetic patients despite a relatively higher morbidity and mortality. We recommend strict perioperative glycemic control, complete revascularization, and BITA use. The authorities must apply a policy to improve early detection of diabetic patients who are at high risk of CAD, establish primary and secondary prevention protocols, and prepare appropriate structures with multi-disciplinary teams. As for practitioners, they have to improve their therapeutic protocols, which must be more aggressive for early management and better diabetic control.

\section{Additional file}

Additional file 1: Table S1. Independent predictors of mediastinitis by binary logistic regression analysis.

\begin{abstract}
Abbreviations
A. Fib: Atrial fibrillation; AMl: Acute myocardial infarction; BGL: Blood glucose level; BITA: Bilateral internal thoracic artery; CABG: Coronary artery bypass grafting; CAD: Coronary artery disease; CPB: Cardiopulmonary bypass; DM: Diabetes mellitus; FPG: Fasting plasma glucose; $\mathrm{HbA}_{1} \mathrm{C}: \mathrm{A}_{1} \mathrm{C}$ hemoglobin; IABP: Intra-aortic balloon pump; ICU: Intensive care unit; IT: Insulin-treated; ITA: Internal thoracic arteries; LCOS: Low cardiac output syndrome; LV: Left ventricular; MACCE: Major adverse cardiac and cerebral event; NIT: Noninsulin-treated; NYHA: New York Heart Association; PVAD: Polyvascular atherosclerotic disease; SITA: Single internal thoracic artery; SVG: Saphenous vein graft; VSD: Ventricular septal defect
\end{abstract}

\section{Acknowledgements}

We would like to appreciate the technical assistance of Mr. A. El Fadl for the English writing of the manuscript.

\section{Authors' contributions}

YM, RM, and MA collected the data. YM, AS, and NA performed the statistical analysis and analyzed the data. YM, MD, AHG, and IA designed, drafted, and corrected the manuscript. $Z \mathrm{~L}, \mathrm{AM}, \mathrm{YB}$, and $\mathrm{AB}$ revised the paper. All authors have read and approved the final manuscript.

\section{Funding}

There were no funding sources to support this work.

Availability of data and materials

Please contact the authors for data requests.

\section{Ethics approval and consent to participate}

The study was conducted according to the Helsinki Declaration and approved by the ethics committee of Mohammed $V$ Teaching Military Hospital of Rabat and the Biomedical Research Ethics Committee of Faculty of Medicine and Pharmacy of Rabat-Mohammed V University (CERB: Comité d'Ethique de la Recherche Biomédicale de la Faculté de Médecine et de Pharmacie de Rabat Université Mohammed V ( $n^{\circ}$ CERB_MOR76)). This study is registered in ISRCTN registry (number ISRCTN11781836). Informed written consent was obtained from all participants.

\section{Consent for publication}

This manuscript has been reviewed and approved by all the co-authors and has not been submitted to any other journals for consideration for publication.

\section{Competing interests}

The authors declare that they have no competing interests.

\section{Author details}

${ }^{1}$ Faculty of Medicine and Pharmacy, Mohammed V University, Rabat, Morocco. ${ }^{2}$ Cardiac Surgery Department, Mohammed V Teaching Military Hospital, Hay Riyad, PB 10100 Rabat, Morocco. ${ }^{3}$ Intensive Care of Cardiac Surgery, Mohammed V Teaching Military Hospital, Rabat, Morocco. ${ }^{4}$ Cardiology Department, Mohammed V Teaching Military Hospital, Rabat, Morocco. ${ }^{5}$ Laboratory of Biostatistics, Clinical and Epidemiological Research (LBRCE), Faculty of Medicine and Pharmacy, Mohammed V University, Rabat, Morocco.

Received: 14 August 2019 Accepted: 16 October 2019

Published online: 04 December 2019

\section{References}

1. McGinn JT Jr, Shariff MA, Bhat TM, Azab B, Molloy WJ, Quattrocchi E, Farid M, Eichorn AM, Dlugacz YD, Silverman RA (2011) Prevalence of dysglycemia among coronary artery bypass surgery patients with no previous diabetic history. J Cardiothorac Surg. 6:104. https://doi.org/10.1186/1749-8090-6-104

2. American diabetes association (2017) Standards of medical care in diabetes - 2017. 2. Classification and Diagnosis of Diabetes. Diabetes Care 40(Suppl. 1):S11-S24

3. Tazi MA, Abir-Khalil S, Chaouki N, Cherqaoui S, Lahmouz F, Sraïri JE et al (2003) Prevalence of the main cardiovascular risk factors in Morocco: results of a National Survey, 2000. J Hypertens. 21(5):897-903

4. World Health Organization. Country profiles for diabetes 2016. Available at: http://www.who.int/diabetes/country-profiles/mar_en.pdf.

5. Moutakiallah Y, Benzaghmout K, Aithoussa M, Atmani N, Amahzoune B, Hatim A et al (2014) Coronary surgery under cardiopulmonary bypass in patients with diabetes. Pan Afr Med J. 17:199

6. Serruys PW, Morice MC, Kappetein AP, Colombo A, Holmes DR, Mack MJ, Ståhle E, Feldman TE, van den Brand M, Bass EJ, Dyck NV, Leadley K, Dawkins KD, Mohr FW, for the SYNTAX Investigators (2009) Percutaneous coronary intervention versus coronary-artery bypass grafting for severe coronary artery disease. N Engl J Med. 360(10):961-972

7. Mohr FW, Morice MC, Kappetein AP, Feldman TE, Ståhle E, Colombo A, Mack MJ, Holmes DR Jr, Morel MA, Dyck NV, Houle VM, Dawkins KD, Serruys PW (2013) Coronary artery bypass graft surgery versus percutaneous coronary intervention in patients with three-vessel disease and left main coronary disease: 5-year follow-up of the randomised, clinical SYNTAX trial. Lancet. 381(9867):629-638

8. Farkouh ME, Domanski M, Dangas GD, Godoy LC, Mack MJ, Siami FS, Hamza TH, Shah B, Stefanini GG, Sidhu MS, Tanguay JF, Ramanathan K, Sharma SK, French J, Hueb W, Cohen DJ, Fuster V (2019) for the FREEDOM Follow-On Study Investigators. Long-term survival following multivessel revascularization in patients with diabetes: the FREEDOM follow-on study. J Am Coll Cardiol. 73(6):629-638

9. Lam DW, LeRoith D (2012) The worldwide diabetes epidemic. Curr Opin Endocrinol Diabetes Obes. 19(2):93-96

10. Engoren M, Habib RH, Zacharias A, Schwann TA, Riordan CJ, Durham SJ, Shah A (2008) The prevalence of elevated hemoglobin A1c in patients undergoing coronary artery bypass surgery. J Cardiothorac Surg. 3:63. https://doi.org/10.1186/1749-8090-3-63 
11. Bos M, Agyemang C (2013) Prevalence and complications of diabetes mellitus in Northern Africa, a systematic review. BMC Public Health. 13:387

12. Kogan A, Ram E, Levin S, Fisman EZ, Tenenbaum A, Raanani E et al (2018) Impact of type 2 diabetes mellitus on short- and long-term mortality after coronary artery bypass surgery. Cardiovasc Diabetol. 17(1):151

13. Carson JL, Scholz PM, Chen AY, Peterson ED, Gold J, Schneider SH (2002) Diabetes mellitus increases short-term mortality and morbidity in patients undergoing coronary artery bypass graft surgery. J Am Coll Cardiol. 40(3): 418-423

14. Mohammadi S, Dagenais F, Mathieu P, Kingma JG, Doyle D, Lopez S et al (2007) Long-term impact of diabetes and its comorbidities in patients undergoing isolated primary coronary artery bypass graft surgery. Circulation. 116(11 Suppl):I220-1225

15. Rawshani A, Rawshani A, Franzén S, Eliasson B, Svensson AM, Miftaraj M et al (2017) Mortality and cardiovascular disease in type 1 and type 2 diabetes. N Engl J Med. 376(15):1407-1418

16. Marui A, Kimura T, Nishiwaki N, Mitsudo K, Komiya T, Hanyu M et al (2015) Five-year outcomes of percutaneous versus surgical coronary revascularization in patients with diabetes mellitus (from the CREDO-Kyoto PCI/CABG Registry Cohort-2). Am J Cardiol. 115(8):1063-1072

17. Zalewska-Adamiec M, Bachorzewska-Gajewska H, Malyszko J, TomaszukKazberuk A, Nowak K, Hirnle T et al (2014) Impact of diabetes on mortality and complications after coronary artery by-pass graft operation in patients with left main coronary artery disease. Adv Med Sci. 59(2):250-255

18. Li Z, Amsterdam EA, Young JN, Hoegh H, Armstrong EJ (2015) Contemporary outcomes of coronary artery bypass grafting among patients with insulin-treated and non-insulin-treated diabetes. Ann Thorac Surg. 100(6):2262-2269

19. Wit MA, de Mulder M, Jansen EK, Umans VA (2013) Diabetes mellitus and its impact on long-term outcomes after coronary artery bypass graft surgery. Acta Diabetol. 50(2):123-128

20. Chadli A, El Aziz S, El Ansari N, Ajdi F, Seqat M, Latrech H et al (2016) Management of diabetes in Morocco: results of the International Diabetes Management Practices Study (IDMPS) - wave 5. Ther Adv Endocrinol Metab. 7(3):101-109

21. Thiele RH, Hucklenbruch C, Ma JZ, Colquhoun D, Zuo Z, Nemergut EC et al (2015) Admission hyperglycemia is associated with poor outcome after emergent coronary bypass grafting surgery. J Crit Care. 30(6):1210-1216

22. Doenst T, Wijeysundera D, Karkouti K, Zechner C, Maganti M, Rao V et al (2005) Hyperglycemia during cardiopulmonary bypass is an independent risk factor for mortality in patients undergoing cardiac surgery. J Thorac Cardiovasc Surg. 130(4):1144

23. Furnary AP, Wu Y (2006) Clinical effects of hyperglycemia in the cardiac surgery population: the Portland Diabetic Project. Endocrine practice. Endocr Pract 12(Suppl 3):22-26

24. Ujueta F, Weiss EN, Sedlis SP, Shah B (2016) Glycemic control in coronary revascularization. Curr Treat Options Cardiovasc Med. 18(2):12

25. Magaji V, Nayak S, Donihi AC, Willard L, Jampana S, Nivedita P et al (2012) Comparison of insulin infusion protocols targeting 110-140 mg/dl in patients after cardiac surgery. Diabetes Technol Ther. 14(11):1013-1017

26. Mohammadi S, Dagenais F, Voisine P, Dumont E, Baillot R, Doyle D, Charbonneau E, Kalavrouziotis D (2014) Lessons learned from the use of 1,977 in-situ bilateral internal mammary arteries: a retrospective study. J Cardiothorac Surg. 9:158. https://doi.org/10.1186/s13019-014-0158-9

27. Koshizaka M, Lopes RD, Reyes EM, Gibson CM, Schulte PJ, Hafley GE et al (2015) Long-term clinical and angiographic outcomes in patients with diabetes undergoing coronary artery bypass graft surgery: results from the Project of Ex-vivo Vein Graft Engineering via Transfection IV trial. Am Heart J. 169(1):175-184

28. Iribarne A, Westbrook BM, Malenka DJ, Schmoker JD, McCullough JN, Leavitt BJ et al (2018) Should diabetes be a contraindication to bilateral internal mammary artery grafting? Ann Thorac Surg. 105(3):709-714

29. Vrancic JM, Piccinini F, Camporrotondo M, Espinoza JC, Camou Jl, Nacinovich F et al (2017) Bilateral internal thoracic artery grafting increases mediastinitis: myth or fact? Ann Thorac Surg. 103(3):834-839

30. Taggart DP, Altman DG, Gray AM, Lees B, Gerry S, Benedetto U, Flather M for the ART Investigators (2016) Randomized trial of bilateral versus single internal-thoracic-artery grafts. N Engl J Med. 375(26):2540-2549

31. Deo SV, Shah IK, Dunlay SM, Erwin PJ, Locker C, Altarabsheh SE et al (2013) Bilateral internal thoracic artery harvest and deep sternal wound infection in diabetic patients. Ann Thorac Surg. 95(3):862-869
32. Toumpoulis IK, Theakos N, Dunning J (2007) Does bilateral internal thoracic artery harvest increase the risk of mediastinitis? Interact Cardiovasc Thorac Surg. 6(6):787-791

33. Dorman MJ, Kurlansky PA, Traad EA, Galbut DL, Zucker M, Ebra G (2012) Bilateral internal mammary artery grafting enhances survival in diabetic patients. A 30-year follow-up of propensity score-matched cohorts. Circulation. 126(25):2935-2942

34. Schwartz L, Bertolet M, Feit F, Fuentes F, Sako EY, Toosi MS, Davidson CJ, Ikeno F, King SB (2012) Impact of completeness of revascularization on long-term cardiovascular outcomes in patients with type 2 diabetes mellitus results from the Bypass Angioplasty Revascularization Investigation 2 Diabetes (BARI 2D). Circ Cardiovasc Interv. 5(2):166-173

35. Hlatky MA, Boothroyd DB, Bravata DM, Boersma E, Booth J, Brooks MM et al (2009) Coronary artery bypass surgery compared with percutaneous coronary interventions for multivessel disease: a collaborative analysis of individual patient data from ten randomized trials. Lancet. 373(9670):1190-1197

\section{Publisher's Note}

Springer Nature remains neutral with regard to jurisdictional claims in published maps and institutional affiliations.

\section{Submit your manuscript to a SpringerOpen ${ }^{\circ}$ journal and benefit from:}

- Convenient online submission

- Rigorous peer review

- Open access: articles freely available online

High visibility within the field

- Retaining the copyright to your article

Submit your next manuscript at $\boldsymbol{\sim}$ springeropen.com 